\title{
Biomecânica hoje: enquadramento, perspectivas didácticas e facilidades laboratoriais
}

\author{
J. Paulo Vilas-Boas \\ Faculdade de Ciências do Desporto e de Educação Física, Universidade do Porto
}

https://doi.org/10.5628/pcd.01.01.48

\section{INTRODUÇÃO}

A Biomecânica do Desporto constitui-se hoje como uma das mais importantes Ciências do Desporto, tendo percorrido um longo e profícuo caminho desde a sua introdução nos currículos desportivos da escola de Leninegrado. A sua intervenção é determinante, nos dias de hoje, em diferentes domínios:

(i) no domínio do mais puro entendimento do movimento desportivo e dos factores que constrangem a sua optimização, pelo que consubstancia uma área decisiva de intervenção no quadro dos sistemas complexos de avaliação e controlo do treino e do potencial de rendimento dos atletas;

(ii) no da simulação de novos movimentos e das respectivas exigências morfo-funcionais, de onde favoreça a inovação e a criatividade em condições objectivas de maior fazibilidade;

(iii) no da promoção da adequação dos materiais e instrumentos de realização desportiva à preservação da saúde e integridade dos praticantes e à maximização das prestações e

(iv) no da prevenção e terapia, reconstrutiva ou não, de lesões desportivas.

Apesar desta importância - e do reconhecimento dela pela generalidade da comunidade académica e profissional -, a Biomecânica parece continuar a ser como que remetida para um "gheto" académico, onde se tende a isolar, ou a ser isolada. Este fenómeno parece-nos apresentar uma etiologia plural. Começa, porventura, pela própria linguagem da Biomecânica, naturalmente escorada na matemática, como veremos, que expurga muitas das tentativas de aproximação, nomeadamente no quadro de uma cultura, ou de culturas, menos "matematizadas", como nos parece ser a nossa. Um segundo factor decorre da natureza da instrumentação tradicionalmente utilizada, normalmente sofisticada, ou de aspecto sofisticado e aparentemente pouco amigável para o utilizador. Finalmente, como terceiro factor, surge talvez o recurso a modelos, tantos deles sobre-simplificações do desportista em movimento, que tendem a apresentar-se como caricaturas da complexidade do movimento ou, em contrapartida, construções tão sofisticadas que são percebidas como... imperceptíveis.

Neste contexto, pensamos, não é estranho que se assista a alguma "exclusão" da Biomecânica.

Todavia, pensamos que esta se deve principalmente a um factor ainda não analisado neste trabalho e muito frequentemente secundarizado: as opções didácticas nas disciplinas de Biomecânica ao nível da Licenciatura. Muitas das vezes a apresentação da matéria mantém-se escorada quase que exclusivamente na aula magistral, muito distanciada do estudante e quantas vezes traduzindo, sobretudo, a vocação circunstancial das preocupações e elucubrações do docente. É assim apresentada como uma matéria "áspera", difícil, matematizada, intangível e inatingível, um domínio a evitar até ao inevitável pelo tradicionalmente pragmático estudante de Educação Física e Desporto. Neste trabalho procuraremos reflectir acerca da "urgência" da Biomecânica no quadro das Ciências do Desporto, recorrendo fundamentalmente ao seu enquadramento enquanto disciplina científica. Passaremos, depois, a tecer algumas considerações 
relevantes acerca do que pensamos dever ser o ensino da Biomecânica ao nível da graduação, para, finalmente, sistematizarmos o momento actual do Laboratório de Biomecânica Dr. André Costa, da Faculdade de Ciências do Desporto e de Educação Física da Universidade do Porto (FCDEF-UP).

\section{A BIOMECÂNICA ENQUANTO DISCIPLINA CIENTÍFICA}

A Biomecânica constitui uma nova disciplina científica em pleno processo de estabelecimento(11) e, portanto, naturalmente carecida de definição e de enquadramento claros e incontroversos.

Segundo Adrian e Cooper(1), a Biomecânica constitui a disciplina científica que procura medir, modelar, explicar, equacionar, categorizar e catalogar os padrões dos movimentos das criaturas vivas. Os autores consideram ainda que se trata da "Física do movimento humano ou de outros seres vivos" (2, p.5) $\mathrm{e}$ reconhecem diferentes áreas de subespecialidade da Biomecânica: desde os vários tipos de Biomecânica animal, até à Biomecânica humana.

No domínio específico da Biomecânica humana, Adrian e Cooper(1) distinguem ainda a Biomecânica de porções seleccionadas do corpo (Biomecânica muscular, óssea, articular, respiratória, etc.) e a Biomecânica do corpo como um todo. Neste último caso reconhecem diferentes ramos: (i) Biomecânica desportiva; (ii) Biomecânica ocupacional; (iii) Biomecânica de reabilitação, etc..

A perspectiva de Adrian e Cooper(1) é, naturalmente, uma perspectiva abrangente da Biomecânica. Parecenos, porém, que um escrutínio rigoroso do enquadramento epistemológico destas perspectivas pode conduzir ao reconhecimento de tangências e conflitualidades com outros espaços científicos, como por exemplo a bioenergética, o que nos leva a preferir uma perspectiva algo mais restritiva.

Reconhecemos, todavia, que a tendência para um progressivo alargamento tentacular às questões todas, ou apenas físicas - que condicionam o entendimento do movimento dos sistemas biológicos, é uma tendência naturalmente emergente da inexorável propensão para a transdisciplinaridade na ciência contemporânea.

Como contraponto à perspectiva mais abrangentes anteriormente referida, Hay ${ }^{(5)}$ preconiza uma acepção que, em nossa opinião, parece excessivamente restritiva, ao circunscrever a Biomecânica ao movimento humano. No entanto, o autor propõe uma definição desta disciplina que nos parece a um tempo pragmática, simples e significante, sobretudo se eliminarmos a restrição que impõe à esfera humana: "A Biomecânica é a ciência que examina as forças internas e externas que actuam sobre o corpo humano e os efeitos que elas produzem" (5, p.3). Esta definição, exactamente amputada da circunscrição à esfera humana e, portanto, mais adequada à nossa perspectiva, foi adoptada por Nigg(10) num dos mais interessantes manuais de Biomecânica actualmente disponíveis: "A Biomecânica é a ciência que examina as forças que actuam sobre e no interior de uma estrutura biológica e os efeitos produzidos por essas forças". De facto, somos da opinião de que a Biomecânica é a disciplina científica que estuda a mecânica dos sistemas biológicos, não contemplando, por isso, nem todos os problemas físicos envolvidos, nem tão pouco se ocupando de todas as inerências do movimento, nomeadamente, por exemplo, as bioquímicas, etc..

São, porém, preocupações da Biomecânica os efeitos físicos das forças, internas ou externas que actuam sobre o sistema biológico considerado, bem como a capacidade e condições para que o sistema em causa possa produzir forças que actuem de determinada forma sobre outros corpos. Assim, para além de medir as forças em questão e os seus efeitos imediatos sobre os movimentos segmentares e os do "corpo todo", a investigação Biomecânica deve lidar também com os factores mecânicos que constrangem ou coadjuvam esses movimentos e com os efeitos biológicos das forças produzidas sobre os tecidos (crescimento, desenvolvimento, degenerescência, lesões de sobrecarga e sobreutilização, etc.).

Em suma, a Biomecânica deve deter-se sobre a funcionalidade mecânica dos órgãos, aparelhos e sistemas dos seres vivos, sobre a sua cargabilidade mecânica, sobre os limites da sobrecarga e da lesão e sobre os factores que afectam a performance, incluindo a desportiva e, portanto, envolvendo, o treino em si mesmo, os meios auxiliares de treino, o equipamento desportivo e a técnica desportiva. A Biomecânica consiste, então, numa matéria de inquestionável relevância curricular para cursos de Desporto e de Educação Física, quer ao nível de 
licenciatura, quer de pós-graduação, importando conferir-lhe a importância que lhe é devida. Admite-se com facilidade, portanto, que ao invés de preconizarmos uma Biomecânica fechada sobre si mesma, a vemos antes como uma disciplina necessariamente vocacionada para a convivência com outras, especialmente quando é o desporto que é assumido como objecto. Isto, porém, é diferente de se imaginar ou aceitar que a Biomecânica possa reclamar para si mesma o contributo específico dessas outras disciplinas. Este enunciado transpõenos para uma questão que importa abordar aqui: as relações da Biomecânica e da Cinesiologia. Cinesiologia significa, literalmente, a ciência do movimento(5) e está, reconhecidamente, na origem da Biomecânica. Adrian e Cooper(1), de resto, sublinham que, na sua forma mais pura, Cinesiologia é sinónimo de Biomecânica.

A Cinesiologia terá tido início nos finais da primeira metade do século XX, sendo a publicação por Wells, em 1950, da obra Kinesiology(12), considerada um marco por individualidades como Hudson(7). Nos seus primeiros tempos, a Cinesiologia descrevia o conjunto de ciências que tratavam da estrutura e função do aparelho locomotor, nomeadamente do sistema ósteomuscular. Mais tarde incorporou também o estudo dos princípios mecânicos aplicáveis ao movimento humano, para, mais tarde ainda, ganhar muito maior abrangência ao agrupar todas as ciências que tratavam o movimento humano(5).

Nesta nova fase de grande abrangência epistemológica, o termo "Cinesiologia" serviu - e ainda serve - para designar, inclusivamente, cursos, universitários ou não, faculdades e departamentos universitários, perdendo, ou vendo atenuada, a sua capacidade significante para designar o seu quadro de preocupações originais: a estrutura e função do aparelho locomotor e os princípios mecânicos envolvidos.

Terá sido a partir desta inadequação epistemológica do termo que foram propostos outros para designar a área de estudos em causa, de entre os quais Hay(5) destacou seis: Antropomecânica, Antropocinética, Biodinâmica, Homocinética, Cinantropologia e Biomecânica. Destes, prevaleceu a designação de Biomecânica, a qual, segundo o mesmo autor, obteve mais aceitação na comunidade científica.
Neste quadro evolutivo da Biomecânica, é curiosa a perspectiva de Hudson(7), autor que advoga o reconhecimento de duas fases distintas na evolução da Biomecânica: (i) a Biomecânica Pré-moderna (19401965), que associa à Cinesiologia e na qual reconhece uma acentuada influência da Anatomia e da Fisiologia, a par da Física, onde o estudo da cinemática segmentar e dos padrões motores anatomo-funcionais assumem especial relevância e (ii) a Biomecânica Moderna (pós 1965), alicerçada sobretudo na mecânica e no desenvolvimento e disponibilização de meios tecnológicos que tornam fazível a investigação reducionista sofisticada, caracterizando-se pelo complemento da cinemática pela dinâmica e pelo estabelecimento de pontes com a termodinâmica e a bioenergética, através de entidades como o trabalho e a potência. Esta ponte para a termodinâmica pressupõe o entendimento do organismo biológico, do animal, do homem e do desportista, como sistemas termodinâmicos e a performance desportiva como uma emergência de processos optimizados de aporte energético e de rendimento termodinâmico (eficiência), seja bioquímico, seja biomecânico.

Esta última perspectiva, de resto, parece-nos bem interessante, isto porque até nas modalidades desportivas abertas, onde o processamento da informação e a tomada de decisões assumem um papel crítico, a perspectiva termodinâmica não deve ser vista como uma aproximação redutora, sobretudo se atendermos a alguns contributos modernos no domínio das teorias da informação e dos sistemas, que consubstanciam um desafio filosófico à $2^{\mathrm{a}}$ lei da termodinâmica: o efeito neguentrópico da informação(9).

$\mathrm{O}$ enunciado anterior remete-nos directamente para a seguinte questão: serão exclusivamente do foro da mecânica os contributos possíveis da Física para uma abordagem interdisciplinar do movimento humano, especialmente do movimento desportivo? Parece-nos claro que a resposta à questão anterior é negativa, abrindo um inequívoco espaço de (re)alargamento da Biomecânica e dando lugar à Biofísica do Desporto. A este propósito, de resto, é curioso constatar que Hay(5), imediatamente após a sua proposta de definição para a Biomecânica, esclarece que nenhuma das definições disponíveis era 
universalmente reconhecida e que se destacavam, já então, zonas de investigação mais vastas do que aquelas que as definições atribuíam à Biomecânica, como que se a própria designação, a exemplo da Cinesiologia, estivesse já a cair em desuso.

$\mathrm{O}$ anteriormente exposto confere especial sentido à perspectiva abrangente da Biomecânica que é expressa no programa actual da disciplina de Biomecânica do Curso de Licenciatura em Desporto e Educação Física da FCDEF-UP e arriscar-nos-íamos mesmo a preconizar a substituição da disciplina de Biomecânica por uma explicitamente consagrada à Biofísica referenciada ao desporto. Implicitamente aceitamos que, pelo menos aparentemente, se incorreria no risco de retomar a saga aglutinadora da Cinesiologia, mas ganhava-se, naturalmente, em esclarecimento epistemológico e em questões mais pragmáticas, como o mais fácil estabelecimento de pontes com outras áreas fundamentais do curso, como as disciplinas de Fisiologia. Ganhava-se ainda nos domínios da integração de conhecimentos e da construção de uma concepção unitária, por parte do estudante, dos factores determinantes do rendimento desportivo-motor.

\section{O ENSINO DA BIOMECÂNICA E/OU DA BIOFÍSICA NA GRADUAÇÃO ACADÉMICA EM CIÊNCIAS DO DESPORTO E EM EDUCAÇÃO FÍSICA}

Seja restringido à Biomecânica, seja perspectivando abordagens mais vastas no domínio da Biofísica, o ensino da Cinesiologia, ou da Biomecânica, não tem sido objecto de investigação aturada, inclusivamente no que respeita ao ensino desta disciplina em cursos de graduação em Desporto e Educação Física.

Estão, todavia, disponíveis alguns dados e perspectivas na literatura, que nos parecem dever ser analisados e reflectidos, mesmo porque nos parecem reportar-se a problemas comuns à maioria dos cursos e das instituições que contemplam esta disciplina, onde a Biomecânica é, tradicionalmente uma das "disciplinas-problema".

Davis(3) reportou dados de extrema relevância relativamente ao papel da Biomecânica na formação de profissionais de Educação Física e Desporto graduados pelas universidades, nomeadamente relativos à forma como percebem essa importância e à impressão que lhes sobrou dos respectivos cursos.
Das suas conclusões destaca-se:

(i) $82 \%$ dos inquiridos consideram que a Biomecânica tem valor prático para o entendimento da técnica desportiva;

(ii) $66 \%$ não gostaram da complexidade e nível de abstracção teórica da Matemática e da Física envolvidas;

(iii) $45 \%$ dos sujeitos consideraram ser muito difícil acompanhar as componentes Matemática e Física da disciplina;

(iv) $41 \%$ dos sujeitos referem falta de confiança para referir princípios biomecânicos quando ensinam ou treinam atletas;

(v) mais de $33 \%$ do grupo refere ter dificuldades substanciais para ler artigos de investigação em Biomecânica.

$\mathrm{Na}$ obra referida(3), o autor coloca em questão a adequação dos conteúdos e dos métodos de ensino da Biomecânica aos objectivos da disciplina, nomeadamente em cursos de graduação em Desporto e Educação Física. Considera, nomeadamente, que se faz apelo exagerado à linguagem matemática e à resolução de problemas, valorizando-se menos a compreensão do movimento numa perspectiva Biomecânica; isto é, valorizandose menos uma biomecânica "qualitativa", que considera mais apropriada para a formação académica inicial.

Segundo Davis(3), a intenção de preparar os estudantes para estudos avançados, a fertilização cruzada dos conceitos e dos problemas na era da interdisciplinaridade e a perseguição da credibilidade académica da área científica em questão, terão levado a revestir a disciplina de Biomecânica de uma complexidade exacerbada, implicando um muito exigente background nas ciências Físicas e Matemáticas e envolvendo conteúdos de reduzida utilidade prática. Complementarmente, o autor considera ainda que este quadro tende a ser perpetuado, uma vez que, quando os docentes são chamados a elaborar um programa para uma disciplina de Biomecânica, é comum, na ausência de informação alargada e de uma verdadeira massa crítica em Pedagogia da Biomecânica, serem tentados a observar e adoptar os conteúdos e métodos dos 
cursos estabelecidos, refrescando-os apenas através das suas próprias experiências. Só mais raramente se pode assistir a uma verdadeira exercitação da capacidade criativa dos docentes.

A situação anteriormente descrita foi considerada por Davis(3) como pouco consentânea com a conclusão da First National Conference on the Teaching of Kinesiology, que preconizava:

"A primeira função dos cursos de graduação é a de dotar os estudantes do conhecimento e experiência necessários para conduzirem análises qualitativas úteis" (6).

Curiosamente, Knudson, Morrison e Reeve( 8$)$ concluíram, na mesma perspectiva, que três cursos de Cinesiologia com incidências diferentes, dois de natureza cinesiológica, mais tradicionais, e um mais especificamente biomecânico, não proporcionaram qualquer efeito significativo na capacidade dos estudantes para promoverem análises qualitativas de três habilidades motoras.

Se às possibilidades e constatações antes enunciadas se acrescentar a plausível dificuldade de muitos professores de Educação Física e treinadores falharem na aplicação de conceitos biomecânicos à análise das habilidades motoras(2), entende-se bem que se possa reconhecer aquilo que Davis(3) definiu como um dilema pedagógico em Biomecânica para cursos de graduação, o qual decorre do reconhecimento de duas aproximações possíveis à disciplina(3, p.16):

“(1) Biomaximecânica - Uma aproximação que enfatiza as ciências Matemáticas e Físicas por forma a melhor preparar os estudantes para estudos avançados.

(2) Biominimecânica - Uma aproximação que consiste num mínimo de teoria e tanta aplicação quanto possível dessa teoria aos problemas encontrados na prática."

O esclarecimento deste dilema no presente contexto passa, necessariamente, por um exercício especulativo e qualquer tomada de posição decorrerá, inevitavelmente, mais do arbítrio subjectivo de cada um do que do escrutínio rigoroso dos escassos contributos pedagógico e didácticos disponíveis. Em nossa opinião, o programa e os métodos de ensino da disciplina de Biomecânica devem, naturalmente, ser conformes à possibilidade de dar satisfação aos objectivos da disciplina científica em si mesma; mas devem ter em consideração que a maioria dos estudantes se vai consagrar às carreiras de Professor de Educação Física e Desporto ou de Treinador Desportivo, importando, portanto, que os programas e os métodos de ensino sejam capazes de potenciar as competências dos estudantes para a observação, a análise e avaliação subjectivas da técnica e para a prescrição fundamentada do exercício, de meios auxiliares de treino, ou de determinado equipamento desportivo.

Devem ainda atender à necessidade de salvaguardar a natural hierarquização de diferentes níveis de ensino, permitindo que se reserve para os cursos de pós-graduação, de mestrado nomeadamente, o aprofundamento dos conteúdos mais essencialmente teóricos e especialmente vocacionados para os estudos avançados, para a modelação teórica e para a investigação científica.

Esta nossa perspectiva substancia-se, fundamentalmente, na carência de bases físicas e matemáticas na formação prévia dos estudantes, na escassez dos tempos lectivos para as proporcionar e na importância curricular da Biomecânica em Educação Física e Desporto. Naturalmente que, caso os estudantes pudessem dispor de uma disciplina propedêutica, por exemplo de Física Geral, ou de Métodos Matemáticos, o quadro da questão seria substancialmente alterado.

Preservando as devidas proporções, estamos de acordo com Fiolhais(4) quando sublinha, nas primeiras páginas de Física Divertida, a necessidade de democratizar a Física valorizando a sua vertente intuitiva e eminentemente significante em termos quotidianos e secundarizando a expressão Matemática sem que, contudo, se renegue esta como linguagem natural de expressão do conhecimento da Física. Quer isto dizer que preconizamos, ao nível de licenciatura, a valorização de uma Biominimecânica, sem que o "mini" possa, aprioristicamente, encerrar qualquer valoração depreciativa, nomeadamente da credibilidade académica da disciplina. De facto, tal como Davis(2), não queremos com esta opção dar azo à tentação de transformar a Biomecânica em 
"Bionãomecânica”(3,p.116), mas tão só torná-la mais adequada às condições iniciais e ao nível de ensino e mais consequente no quadro da formação das competências profissionais dos estudantes, nomeadamente no que respeita ao reconhecimento e valorização dos contributos da Biomecânica para o desenvolvimento da qualidade do seu desempenho profissional.

Se, efectivamente, se aceita que os contributos da Biomecânica são essenciais para a optimização da performance desportiva, notadamente das modalidades individuais, cíclicas e fechadas, mas também das demais (ainda que à sua medida), então há que garantir que Professores de Educação Física e Treinadores possam procurar entender e fazer uso seguro e consistente dos seus postulados e das suas novas conquistas científicas. Para tal, o que começa por ser importante é que aqueles entendam a disciplina e os seus possíveis contributos, ao mesmo tempo que desenvolvem as competências imprescindíveis à sua utilização para prescrever exercícios e correcções e para avaliar o desempenho de alunos e atletas. Só depois, pensamos, é que é importante que desenvolvam conhecimentos que lhes permitam a realização de estudos aprofundados. Naturalmente que os Professores e Treinadores têm também de fomentar esta convergência, procurando, valorizando e favorecendo um continuado crescimento da respectiva formação neste campo, sob pena da informação possível e dos contributos possíveis não serem mais do que quase nada. Este esforço, entretanto, parece-nos ser tanto mais facilitado, quanto mais inequívoco for o reconhecimento, por um lado, da utilidade da Biomecânica e das mais valias que acrescenta e, por outro, da importância de cada um se sentir efectivamente capaz de a utilizar de forma consequente. Em suma, os estudantes de hoje e os profissionais de amanhã deverão estar disponíveis para a potenciação do seu conhecimento, mas os biomecânicos, docentes e investigadores, deverão estar preparados para suavizar o seu discurso, por forma a disponibilizar os seus contributos de forma amigável e perene.

No que respeita ao ensino propriamente dito, esta perspectiva impõe, sobretudo, uma aproximação didáctica diferenciada e não tanto uma alteração radical de conteúdos. Naturalmente permite a abordagem a mais conteúdos, uma vez que se procura uma aproximação mais intuitiva e menos aprofundada dos mesmos.

A Matemática é introduzida de forma mais subtil e é conferida mais ênfase à resolução de problemas à medida que vão surgindo, por oposição à sistemática colocação de problemas aos estudantes para resolução e, muitas vezes, com reduzida contextualização desportiva. Uma forma de o conseguir será, por exemplo, partir da observação do movimento desportivo e da sua descrição, para a respectiva explicação, eventual modelação e simulação ulterior, dois passos que poderão, com facilidade e coerência, ser remetidos para estudos de pós-graduação.

\section{MOMENTO ACTUAL DO LABORATÓRIO DE BIOMECÂNICA DR. ANDRÉ COSTA}

Em Julho de 1997 começou a ser implementada uma nova perspectiva integrada de dotação e operacionalização da instrumentação para a avaliação e investigação biomecânicas do Laboratório de Biomecânica Dr. André Costa da FCDEF-UP. Tomando por referência o antes exposto e, principalmente, a necessidade de "laboratorização" do ensino da Biomecânica, seja a nível de graduação, seja de pós-graduação, procurou-se que esta instrumentação tocasse os grandes domínios de intervenção, nomeadamente:

(i) a cinemetria;

(ii) a dinamometria e

(iii) a electromiografia.

Esta nova perspectiva do ensino da Biomecânica na FCDEF-UP tornou-se possível dada a convergência de um conjunto de factores de desenvolvimento, a saber:

(i) facilidades de espaço e de interacção proporcionadas pelas modernas instalações da Faculdade;

(ii) reforço do orçamento da Faculdade e gestão orçamental sensível ao desenvolvimento científico e tecnológico da instituição;

(iii) reconhecimento, pela a comunidade escolar, da necessidade de dotar a Faculdade de um Laboratório suficientemente equipado para 
proporcionar quer a mais adequada leccionação das disciplinas de Biomecânica aos níveis graduado e pós-graduado, quer as infraestruturas necessárias à implementação de programas de investigação Biomecânica nos diferentes contextos desportivos e afins;

(iv) reforço do pessoal docente e não docente afecto ao Laboratório;

(v) valorização e fomento de interfaces de competências, chamando à colaboração directa sujeitos com diferentes formações e sensibilidades e

(vi) fomento de parcerias com outras faculdades da Universidade do Porto, nomeadamente com as de Engenharia e de Ciências.

Aos factores de desenvolvimento referidos juntou-se ainda uma máxima que reputamos da maior utilidade: a ideia de que, mediante a impossibilidade de recurso a soluções tecnológicas comerciais altamente especializadas, importaria potenciar o desenvolvimento de soluções próprias que, por sua vez, pudessem vir a abrir espaços de inovação e desenvolvimento.

Consideramos hoje, três anos volvidos sobre o início da reforma em causa, que nos encontramos próximo do que poderíamos classificar como o "início da primeira fase adulta" de uma estrutura desta natureza: um Laboratório Universitário de Biomecânica do Desporto, vocacionado a um tempo para a docência, para a investigação científica, para o desenvolvimento tecnológico e para a prestação de serviços à comunidade.

\subsection{Meios e potencial para a intervenção Biomecânica}

Em traços gerais, a instrumentação já disponível no Laboratório permite um amplo leque de abordagens biomecânicas (Figura 1), integradas ou não, que permitem a mais conveniente e actualizada problematização da actividade física e desportiva neste domínio científico. Trata-se, na maioria dos casos, de instrumentação comercial, apesar de se contar já com equipamento de desenvolvimento próprio, nomeadamente os eléctrodos activos para
Electromiografia (EMG) diferencial de superfície. O desenvolvimento de equipamento vem permitindo minorar os custos de dotação do Laboratório, sabidamente pesados e especialmente difíceis de suportar pelos reduzidos orçamentos de Faculdades de não muito grande dimensão, como é o caso. No entanto, o actual equipamento do Laboratório traduz já um investimento avultado, quer em termos absolutos, quer, inclusivamente, em termos relativos, o que diz bem do esforço desenvolvido pela FCDEFUP no domínio da implementação de estruturas laboratoriais.

Uma outra solução para minorar os custos de montagem de uma infra-estrutura desta natureza, consiste no desenvolvimento ou configuração de software para o processamento do sinal produzido pelos vários instrumentos, em alternativa à opção pelo software original. Para além da redução de custos conseguem-se assim algumas soluções interessantes de sincronização de instrumentação diversa, tantas vezes difícil e muitas vezes decisiva para a complexa investigação biomecânica do movimento desportivo. Neste particular, o Laboratório recorre normalmente a uma placa de conversão analógico / digital (A / D) Biopac e ao respectivo software (Acqknowledge), especificamente formatado para os diferentes inputs.

Por último, registe-se que uma das tarefas fundamentais do Laboratório consiste no desenvolvimento de pequeno material de suporte à implementação das situações experimentais dos diferentes protocolos de investigação (suportes de plataforma de força e células de carga, estrados para análise dinâmica da marcha, suportes para câmaras de vídeo, referências de calibração planar e espacial, soluções de sincronização de sinal vídeo, áudio e dinamométrico, etc.).

No domínio da investigação científica, o Laboratório tem procurado desenvolver a sua actividade em articulação estreita com os diferentes Gabinetes da FCDEF-UP, quer desenvolvendo projectos autónomos, quer dando resposta à necessidade de implementação de projectos com vista à realização de provas académicas. 


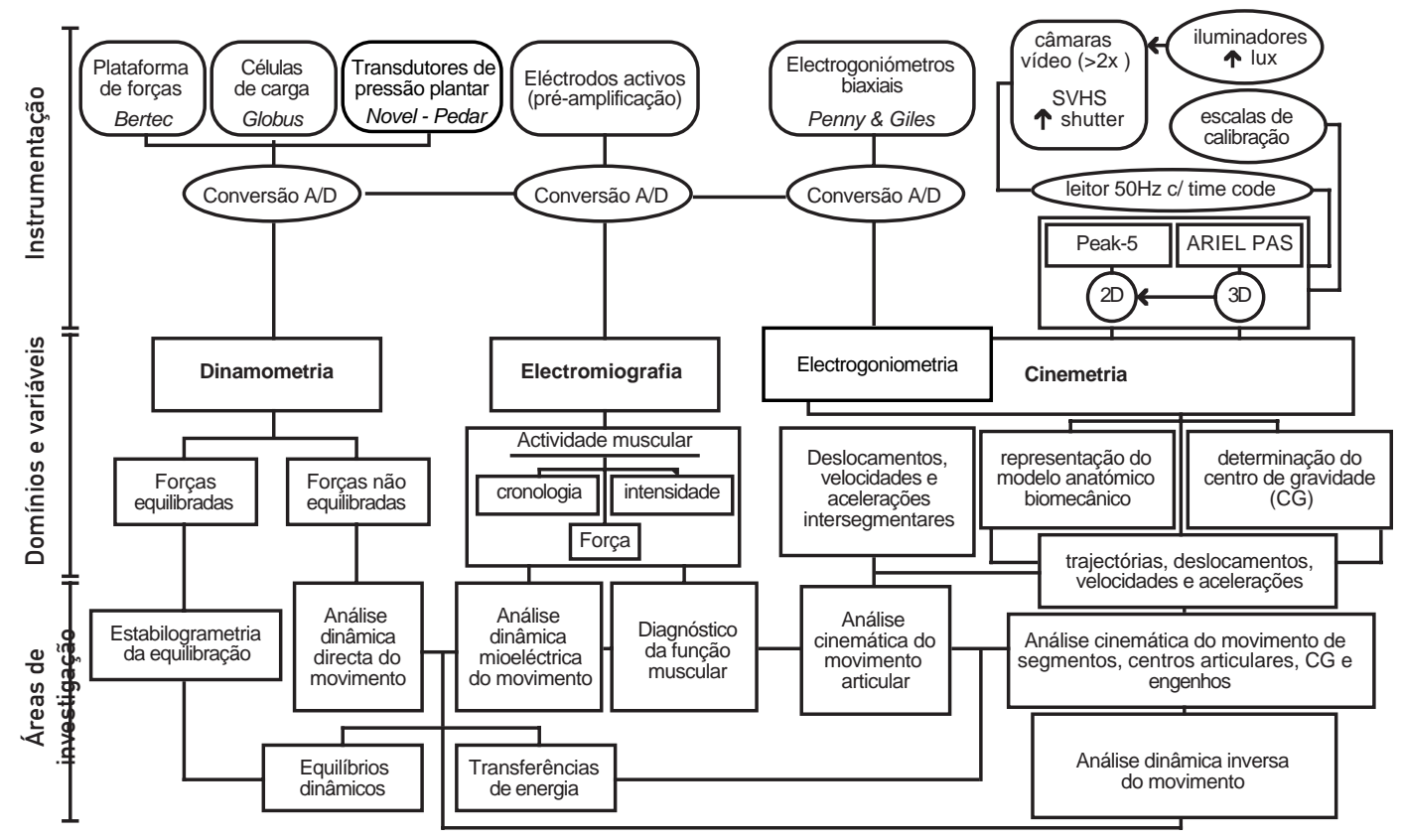

Figura 3. Representação esquemática dos domínios, variáveis e áreas de investigação Biomecânica susceptíveis de estudo através da instrumentação disponível no Laboratório.

A sua actividade estende-se também à cooperação com outras instituições e pessoas, desde clubes desportivos, associações regionais e federações, passando por hospitais e outras instituições universitárias, principalmente promovendo a investigação e reflexão biomecânicas, procurando sempre o fomento da mais sã convivialidade académica e científica e procurando extrair o maior número possível de mais valias, nomeadamente decorrentes do contacto com diferentes saberes, problemas e perspectivas, para o desenvolvimento da adequação desta estrutura ao tecido social e desportivo em geral e ao tecido universitário em particular. 


\section{REFERÊNCIAS}

1. Adrian, M. J. e Cooper, J. M. (1989). The biomechanics of human movement. Benchman Press, Inc., Indianapolis, Indiana. 2. Brown, E. W. (1982). Visual evaluation techniques for skill analysis. JOPERD, Jan: 15-22.

3. Davis, K. (1984). Biomaximechanics or biominimechanics a pedagogical dilemma. Journal of Human Movement Studies, 10: 115-122.

4. Fiolhais, C. (1994). Física divertida. Gradiva, Lisboa.

5. Hay, J. G. (1978). The biomechanics of sport tecniques. Prentice Hall, Inc., Englewood Cliffs.

6. Hay, J. G. (1979), The challenge of change for physical education in the 1980's: a biomechanical viewpoint. Comunicação apresentada ao Annual Meeting of the American Academy of Physical Education, New Orleans, Louisiana.

7. Hudson, J. L. (1991). Recidivistic biomechanics: reclaiming the questions. In: J. D. Wilkerson, E. Kreighaum e C. L. Tant (eds.). Teaching kinesiology and biomechanics in sports, pp. 3-6. Kinesiology Academy of NASPE, Iowa State University, Ames. 8. Knudson, D. V.; Morrison, C, e Reeve, J. (1991). Effect of undergraduate kinesiology courses on qualitative analysis ability. In: J. D. Wilkerson, E. Kreighaum e C. L. Tant (eds.). Teaching kinesiology and biomechanics in sports, pp. 17-20. Kinesiology Academy of NASPE, Iowa State University, Ames. 9. Morin, E. (1981). O paradigma perdido: a natureza humna, Publicações Europa-América, Mem Martins.

10. Nigg, B. M. (1994). Definition of biomechanics. In: B. M. Nigg. e W. Herzog (eds.), Biomechanics of the musculo-skeletal system, p. 2. John Wiley \& Sons, Chichester. 11. Nigg, B. M. e Herzog, W. (1994). Biomechanics of the musculo-skeletal system. John Wiley \& Sons, Chichester. 12. Wells, K. F. (1950). Kinesiology. W. B. Saunders, Philadelphia. 